\title{
Staphylococcus aureus Toxins: From Their Pathogenic Roles to Anti-virulence Therapy Using Natural Products
}

\author{
Min-Kyung Kim
}

Received: 14 February 2019 / Revised: 27 March 2019 / Accepted: 28 March 2019

(C) The Korean Society for Biotechnology and Bioengineering and Springer 2019

\begin{abstract}
Staphylococcus aureus (S. aureus) produces a wide variety of toxins that cause various diseases in humans. S. aureus toxins are divided into three categories; (i) superantigens (SAgs) that interfere with receptor function and cause toxic shock syndrome (TSS) or staphylococcal food poisoning (SFP), (ii) exfoliative toxins (ETs) that destroy epidermal barrier functions and cause staphylococcal scalded skin syndrome (SSSS), and (iii) cytotoxins that cause cell lysis. Recently, anti-toxin neutralizing agents have been engineered and proven to be effective in preventing or treating staphylococcal diseases. However, neutralization of a single toxin may not sufficiently protect the host from $S$. aureus infection. Biofilm formation and the pathogenesis of $S$. aureus are closely associated with accessory gene regulator-quorum sensing ( $a g r-\mathrm{QS})$ system that controls the expressions of many virulence factors including exotoxins. In addition to anti-toxin antibodies, indirect approaches involving targeting of the agr-QS system are considered a novel means of inhibiting the virulence of $S$. aureus and controlling various diseases caused by the pathogen. This review summarizes basic concepts of the pathogenic roles of $S$. aureus toxins, the molecular features of the agr-QS system, and of natural product-based anti-virulence therapies that target virulence, rather than growth.
\end{abstract}

Keywords: staphylococcus aureus, toxins, pathogenesis, anti-virulence therapy, natural products

Min-Kyung Kim

Department of Pathology, Dongguk University College of Medicine, Gyeongju 38066, Korea

Tel: +82-54-703-7810; Fax: +82-54-770-2447

E-mail:minkyungk76@naver.com

\section{Introduction}

Staphylococcus aureus ( $S$. aureus) is a gram-positive bacterium and produces a wide variety of toxins that cause various diseases, which range from mild skin infections to systemic, life-threatening diseases [1]. The virulence factors produced by $S$. aureus include secreted proteins (e.g., superantigens (SAgs), exfoliative toxins (ETs) and cytotoxins), enzymes (e.g., proteases, staphylokinase and coagulase), and surface proteins (e.g., protein A, fibronectins, collagen adhesion and clumping factors) [2-4]. In this review toxins are defined as secreted proteins that directly or indirectly harm the host and cause diseases.

Toxins secreted by $S$. aureus can be divided into three categories, clinically important two exotoxins and cell membrane-damaging cytotoxins; (i) SAgs that interfere with receptor function, (ii) ETs that destroy epidermal barrier function, and (iii) cell membrane-damaging cytotoxins that act in a receptor-dependent or receptor-independent fashion [5]. These toxins mainly modulate host immune response by interfering with the receptor functions of immune cells or facilitate tissue penetration by destroying intercellular junctions or host cell membranes. Many virulence factors, including exotoxins, are expressed under the control of the accessory gene regulator-quorum sensing ( $a g r$-QS) system, which is closely associated with the pathogenesis and biofilm formation by $S$. aureus and with antibiotic resistance [6-8].

S. aureus rapidly acquires antibiotic resistance, and the emergence of multidrug-resistant strains is an enormous burden. It has been reported the annual death toll due to antibiotic-resistant infections has reached 10 million, and that in 2050 it will exceed the number of deaths attributed to cancer [9]. Thus, the appropriate uses of antibiotics and alternative therapeutic approaches have become necessities. 
Recently, anti-toxin antibodies that neutralize individual toxins have been engineered and shown to be effective at preventing or treating staphylococcal diseases [10-12]. Even a combined anti-toxin/antibiotic therapy has been reported to be effective at blocking the progressions of staphylococcal diseases [9]. However, neutralization of a single toxin may not adequately safeguard the host from $S$. aureus infection. Thus novel therapeutic agents targeting the agr-QS system might provide a more effective means of inhibiting the virulence of $S$. aureus and controlling staphylococcal diseases [10-12]. In particular, natural compounds that exhibit anti-toxin properties or target the agr-QS system do not affect bacterial growth or viability, and thus, assuage concerns regarding the emergence of antibiotic-resistant strains [13].

This review summarizes basic concepts concerning the pathogenic roles of various $S$. aureus toxins, including SAgs such as staphylococcal enterotoxins (SEs), which cause staphylococcal food poisoning (SFP), and toxic-shock syndrome toxin-1 (TSST-1), which cause toxic shock syndrome (TSS), ETs, which cause staphylococcal scalded skin syndrome (SSSS), and cytotoxins such as hemolysins, leukotoxin, and phenol-soluble modulins (PSMs), which cause cell lysis, and provides an overview of the molecular mechanism of the agr-QS system [14-16]. Natural productbased anti-virulence therapies that directly or indirectly govern virulence, rather than growth, are also summarized.

\section{Staphylococcus aureus Toxins: Basic Concepts of Their Pathogenic Roles}

\subsection{Superantigens (SAgs) that interfere with receptor function}

Staphylococcal SAgs, the most potent T-cell mitogens, include SEs that have emetic effects after oral administration, and staphylococcal enterotoxin-like toxins (SEls) and TSST-1 that do not have emetic properties [17]. So far, 23 different staphylococcal SAgs have been described: the SEs A-E, G-J, and R-T (SEA-SEE, SEG-SEJ, SER-SET,

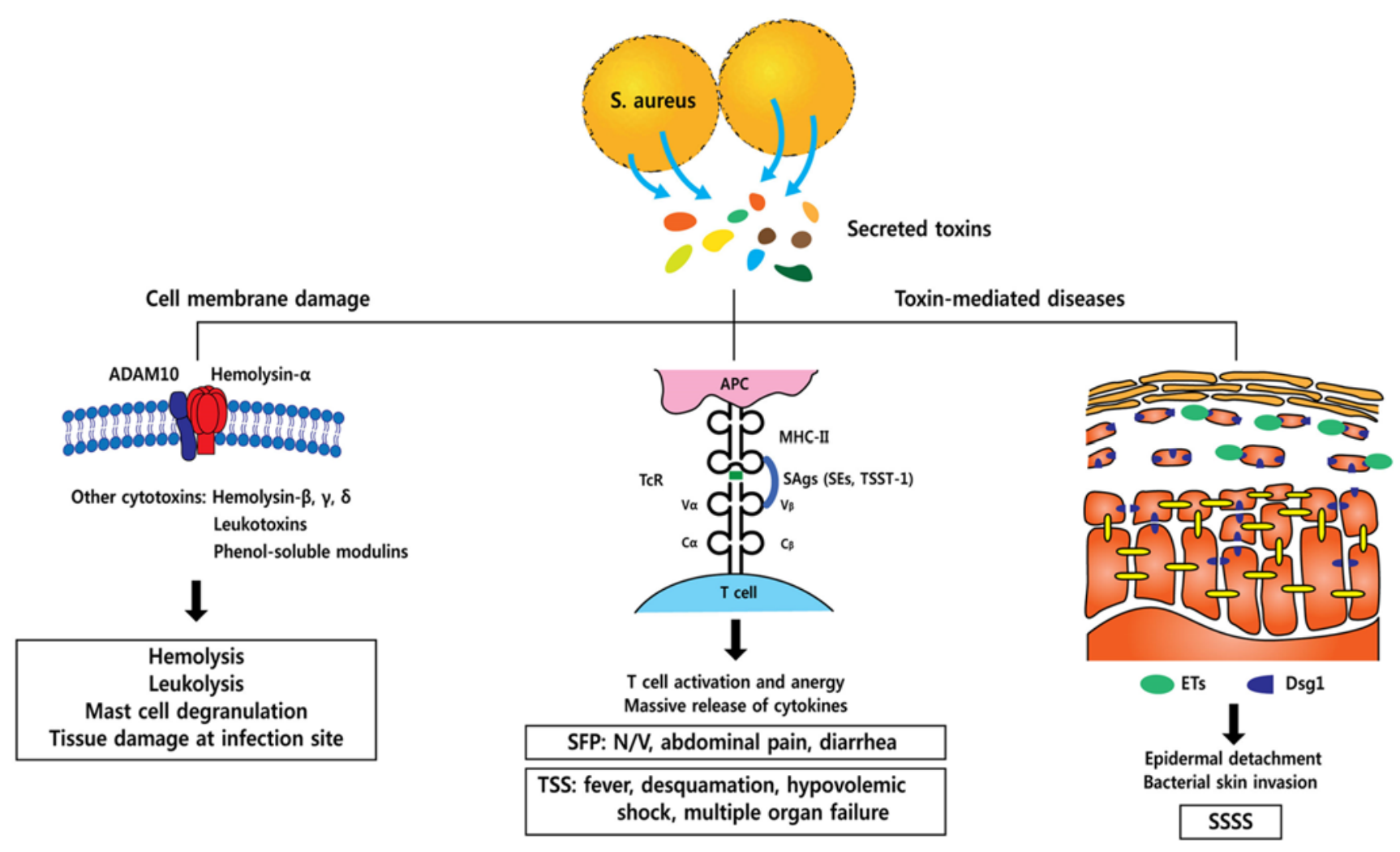

Fig. 1. Schematic diagram of toxin-mediated diseases and of the cell membrane damage caused by Staphylococcus aureus (S. aureus) toxins. Toxin-mediated diseases are induced by superantigens (SAgs) or exfoliative toxins (ETs). SAgs directly cross-link TCR V $\beta$ domains with conserved structures of major histocompatibility complex (MHC) class II, and trigger T cell activation and proliferation without the need for antigen processing. Staphylococcal enterotoxins (SEs) cause staphylococcal food poisoning (SFP), and toxic shock syndrome toxin-1 (TSST-1) causes toxic shock syndrome (TSS). ETs adhere to desmoglein1 (Dsg1) and destroy desmosomal cell attachments, and thus, cause staphylococcal scalded skin syndrome (SSSS). Cell membrane damage is induced by a variety of $S$. aureus toxins including $\alpha-, \beta-, \gamma$-, and $\delta$-hemolysins, leukotoxins and phenol-soluble modulins (PSMs), and eventually leads to hemolysis, leukolysis, and bacterial invasion. 
respectively), the SEIs K-Q and U-X (SEIK-SEIQ, SEIUSEIX) and TSST-1 [15,17,18]. Most SAgs genes are localized on mobile genetic elements (MGEs) and SAg expression regulated by at least four global regulators, $a g r$, $\mathrm{s} a r A, \operatorname{sar} B$ and $\operatorname{sar} R S$, whereas SEIX is encoded on the core genome [18-23].

The action mechanism of SAgs differs from that of conventional peptide antigens. Conventional antigens are internalized and processed by antigen presenting cells (APCs) [24]. T-cells recognize major histocompatibility complex (MHC) class II-restricted antigenic peptide displayed on APC surfaces using hypervariable loops of T-cell receptor (TCR) $\alpha$ and $\beta$ chains [24]. However, SAgs can directly cross-link TCR V $\beta$ domains using conserved MHC class II structures expressed on APCs, and thus, trigger $\mathrm{T}$ cell activation and proliferation without the need of antigen processing (Fig. 1) [25]. That is to say, stimulation of T cells by SAgs is dependent on the composition of the variable region of the TCR $\beta$ chain (V $\beta$ ), not on the antigen specificity of TCR. Furthermore, SAgs trigger cytokine release from activated APCs via MHC class II and mucosal cell barrier disruption [26,27]. Clinically, SAgs result in hypotension by binding directly to MHC class II on endothelial cells which then interact with SEB or TSST-1 and cause the release of vasoactive mediators such as tumor necrosis factor-alpha (TNF- $\alpha$ ) from host leukocytes [28-30]. In the present study, we address SFP and TSS caused by SEs and TSST-1, respectively, although SAgs have been implicated in the pathogenesis of a various human diseases including Kawasaki disease, atopic dermatitis and airway allergies [14,31,32]. Details of various toxins secreted by $S$. aureus are provided in Table 1 .

\subsubsection{Staphylococcal enterotoxins (SEs)}

SEs are secreted toxins of 20 to $30 \mathrm{kD}$ that interfere with intestinal function and cause SFP, which manifests clinically as nausea, vomiting, abdominal pain and diarrhea without signs of systemic toxicity such as fever or hypotension $[33,34]$. SFP is a self-limiting disease that usually resolves within 24 to $48 \mathrm{~h}$ of onset [35]. The mechanism responsible for its emetic activity has not been clearly elucidated, but SE-induced inflammation, rather than SE receptors, has been implicated in the pathogenesis of SFP. The receptors responsible for emetic response to SEs have not been identified, but the clinical symptoms of SFP have been correlated with a number of inflammatory mediators like leukotriene B4 and prostaglandin E2, which are generated in response to SEs [31]. SE-induced gastroenteritis is defined by histologically characteristic inflammatory changes in the gastrointestinal tract [28]. The most severe lesions with hyperemic mucosa are found in the stomach and upper small intestine and are accompanied by neutrophilic infiltrates in epithelium and lamina propria, and damaged brush borders, elongated crypts, and neutrophilic infiltrates in lamina propria are observed in jejunum $[14,36]$. More than 20 SEs (SEA-SEIV) have been identified based on

Table 1. Virulence factors secreted by Staphylococcus Aureus

\begin{tabular}{|c|c|c|c|}
\hline Name & Abbreviation & Function & References \\
\hline Enterotoxins & SEs & $\begin{array}{l}\text { Superantigen activity, gastroenteric toxicity causing } \\
\text { staphylococcal food poisoning }\end{array}$ & {$[14,28,35,36]$} \\
\hline $\begin{array}{l}\text { Toxic shock syndrome } \\
\text { toxin-1 }\end{array}$ & TSST-1 & $\begin{array}{l}\text { Superantigen activity, pro-inflammatory activity, endothelial } \\
\text { toxicity causing toxic shock syndrome }\end{array}$ & {$[14,18,34,39-41]$} \\
\hline $\begin{array}{l}\text { Exfoliative toxins A, B and } \\
\text { D }\end{array}$ & $\mathrm{ETA} / \mathrm{B} / \mathrm{D}$ & $\begin{array}{l}\text { Glutamate-specific serine protease activity that target desmoglein } \\
\text { 1, disruption of epidermal layers causing bullous impetigo, } \\
\text { staphylococcal scalded skin syndrome }\end{array}$ & {$[49,51]$} \\
\hline Hemolysin- $\alpha$ & Hla, $\alpha$-toxin & $\begin{array}{l}\text { Pore-forming activity that lyses RBCs, leukocytes except for } \\
\text { neutrophils }\end{array}$ & {$[43,55-57]$} \\
\hline Hemolysin- $\beta$ & Hlb, $\beta$-toxin & $\begin{array}{l}\text { Sphingomyelinase activity that lyses RBCs, monocytes except for } \\
\text { lymphocytes, granulocytes }\end{array}$ & {$[58,59]$} \\
\hline Hemolysin- $\gamma$ & Hlg, $\gamma$-toxin & $\begin{array}{l}\text { Bi-component pore-forming leukocytolytic activity that lyses } \\
\text { neutrophils, monocytes, macrophages }\end{array}$ & {$[61,62]$} \\
\hline $\begin{array}{l}\text { Leukocidins } \mathrm{D}, \mathrm{E} \\
\text { and } \mathrm{M}\end{array}$ & $\mathrm{LukD} / \mathrm{E} / \mathrm{M}$ & $\begin{array}{l}\text { Bi-component (hetero-oligomeric) pore-forming leukocytolytic } \\
\text { activity that lyses neutrophils, monocytes, macrophages }\end{array}$ & {$[63-67]$} \\
\hline $\begin{array}{l}\text { Leukocidins } A \text { and } B \\
\text { (also called } \mathrm{H} \text { and } \mathrm{G} \text { ) }\end{array}$ & LukAB/-HG & Bi-component pore-forming leukocytolytic activity & {$[67,68]$} \\
\hline $\begin{array}{l}\text { Panton-Valentine } \\
\text { leukocidin }\end{array}$ & PVL & $\begin{array}{l}\text { Bi-component pore-forming leukocytolytic activity that lyses } \\
\text { neutrophils, monocytes, macrophages }\end{array}$ & {$[68,70,71]$} \\
\hline Phenol-soluble modulins & PSMs & Pore-forming cytolytic activity, pro-inflammatory activity & {$[43]$} \\
\hline Hemolysin- $\delta$ & Hld, $\delta$-toxin & $\begin{array}{l}\text { Cytolytic activity that lyses neutrophils, monocytes, mast cell } \\
\text { degranulation }\end{array}$ & {$[53,75]$} \\
\hline
\end{tabular}


antigenic heterogeneity [5,33]. Notably, staphylococcal enterotoxin $\mathrm{B}$ (SEB) is considered a biological weapon, and staphylococcal enterotoxin $\mathrm{C}$ (SEC) promotes infective endocarditis, kidney injury, and sepsis in CA-MRSA strain MW2 infections [37,38].

\subsubsection{Toxic shock syndrome toxin-1 (TSST-1)}

Staphylococcal enterotoxin F (SEF) was renamed TSST-1 [5]. In contrast to SEs, TSST-1 (22-kD) does not cause emesis but rather induces the release of large quantities of pro-inflammatory cytokines, such as interleukin (IL)-1, IL2 , IL-8, and TNF- $\alpha$ from host T cells and macrophages $[14,18,34,39]$. This cytokine storm results in the clinical symptoms of TSS, which include high fever, erythematous rash, desquamation, low blood pressure, and hypovolemic shock leading to multiple organ failure [40,41]. These symptoms are followed by T-cell anergic state, in which Tcells are unable to proliferate, produce IL-2, or even survive [42-44]. These effects of TSST-1 could provide an evolutionary advantage to $S$. aureus by eliminating T-cells that help antibody-producing B-cells exert adaptive immune response [45]. Acute respiratory distress syndrome (ARDS) and disseminated intravascular coagulation (DIC) are common and lethal complications of TSS [27,46]. Prolonged hypovolemic shock is the most prominent histologic feature in fatal cases. In contrast to other forms of septic shock, histopathologic abnormalities in menstruationassociated cases include lymphocytic perivasculitis, hepatic fatty change and periportal triaditis, extensive erythrophagocytosis, and ulcerating vaginitis $[46,47]$.

\subsection{Exfoliative toxins (ETs)}

$S$. aureus ETs include ETA, ETB and ETD, which are encoded on different genetic elements, eta is located on a temperate phage in the genome, whereas $e t b$ is found on plasmids and etd on a genomic island [43]. The expressions of the ETs are regulated by accessory gene regulator (agr) [48]. ETs have glutamate-specific serine protease activity and target a keratinocyte cell-cell adhesion molecule, desmoglein 1 (Dsg1; desmosomal intercellular adhesion molecule) [49]. ETs adhere to Dsg1, destroy desmosomal cell attachments, and thus, cause epidermal detachment of skin epidermis [50]. Disruption of epidermal layers facilitates bacterial skin invasion and causes blistering diseases like bullous impetigo and staphylococcal scalded skin syndrome (SSSS) [51]. SSSS predominantly affects neonates and infants, but adults with renal impairment or immune deficiency are also at risk [52].

\subsection{Cytotoxins}

$S$. aureus produces a variety of toxins that target the cytoplasmic membrane [5,34]. These cytolytic toxins usually form pores in the cell membrane, which results in the efflux of metabolites and molecules, and finally causes cell lysis [5,34]. Membrane-damaging toxins can be classified to two subgroups; toxins that lyse target cells with high specificity in a receptor-dependent fashion, and toxins that interfere with cell membranes in a less specific fashion independently of receptor interactions $[5,34,53,55,56]$.

\subsubsection{Receptor-dependent cytolytic toxins}

$S$. aureus toxins that require receptor interactions for their lytic functions, include hemolysins that target red blood cells $(\alpha-, \beta-, \gamma$-toxin) and leukotoxins that target white blood cells (Panton-Valentine leukocidin (PVL) and leukocidins LukDE and LukAB (LukGH)) [43]. Bi-component toxins are structurally similar to $\alpha$-toxin and belong to the poreforming toxin family [43]. However, $\delta$-toxin is classified as a phenol-soluble modulins (PSMs) and does not require a receptor for its hemolytic activity [53].

\section{A. Hemolysin- $\alpha$ (Hla, $\alpha$-toxin)}

Hla is a water-soluble monomer of $33 \mathrm{kDa}$ and is encoded on the core genome and expressed by $a g r$-regulated systems [54]. Hla has pore-forming and pro-inflammatory properties $[43,55]$. At high concentrations, it forms pores in a receptorindependent fashion whereas at low concentrations, pore formation requires interaction with ADAM10 (a disintegrin and metalloproteinase) in a receptor-dependent fashion $[55,56]$. The heptameric pore-formation of Hla destroys a variety of host cells, including red blood cells, leukocytes (except neutrophils), epithelial cells, and fibroblasts [43,57]. In particular, cleavage of E-cadherin in epithelial adherens junctions and disruption of focal adhesion complexes can reduce epithelium and endothelium barrier functions ultimately paving the way for S. aureus invasion $[55,56]$.

\section{B. Hemolysin- $\beta$ (Hlb, $\beta$-toxin)}

$\mathrm{Hlb}$ is a non-pore-forming toxin but lyses monocytes and erythrocytes except lymphocytes and granulocytes [58]. Although its mode of action is unclear, the sphingomyelinase activity of Hlb may hydrolyze sphingomyelin in the lipid bi-layers of cell membranes, and induce apoptosis [5,59].

\section{Hemolysin- $\gamma$ (Hlg, $\gamma$-toxin)}

$\mathrm{Hlg}$ is a bi-component toxin consisting of polypeptide $\mathrm{S}$ (slow, $\mathrm{HlgA}$ or $\mathrm{HlgC}$ ) and polypeptide $\mathrm{F}$ (fast, $\mathrm{HlgB}$ ). $\mathrm{Hlg}$ is encoded on the core genome [43]. The F component ( $\mathrm{HlgB}$ ) has been proposed to bind to phosphatidylcholine on target cells whereas the $\mathrm{S}$ components (HlgA or $\mathrm{HlgC}$ ) bind to cell membranes and eventually cause lysis [60,61]. The membrane-damaging activity of Hlg is apparent in the 
myleoid lineage, that is, in monocytes, macrophages, and neutrophils [62].

\section{Leukotoxins}

Leukotoxins of $32-35 \mathrm{kDa}$ belong to the bi-component (hetero-oligomeric) Luk toxin family and are composed of one class $\mathrm{S}$ and one class $\mathrm{F}$ protein, which are encoded on the core genome or phage [43]. Class $\mathrm{S}$ and $\mathrm{F}$ proteins oligomerize to form a pore-structure [63]. Class $\mathrm{F}$ protein consists of 5 subunits, namely HlgB, LukF-PV, LukD, LukF'-PV and LukG, and class $\mathrm{S}$ protein consists of six subunits, namely HlgA, HlgC, LukSPV, LukE, LukM, and LukH [63-67]. LukAB (LukGH) is the only leukotoxin capable of lysing neutrophils after phagocytosis without receptor interaction [67,68]. Panton-Valentine leucocidin (PVL) consists of lukF-PV and lukS-PV, which are encoded on phage $[69,70]$. This group of toxins target the cells of lineage such as neutrophils, monocytes, and macrophages $[69,70]$. The leukocytolytic activity of leukotoxins is dependent on receptor interaction. In humans, the receptor for LukED is CCR5 on immune cells, whereas the receptors for PVL and LukAB (LukGH) are C5aR, C5L2, and CD11b, respectively [71-73]. Leukotoxins are presumed supposed to be important for immune evasion by $S$. aureus $[64,67]$. The leukocytotic activity of PVL has been reported to be 100-fold greater than that of other leukotoxins, and relations between PVL and necrotizing pneumonia and skin and soft tissue infections (SSTIs) remain topics of active discussion [74].

\subsubsection{Receptor-independent cytolytic toxins}

As previously mentioned, hemolysin- $\delta$ ( $\delta$-toxin, Hld) is a family of PSMs, which do not require receptor interaction for cytolytic activity [53]. In addition, $\delta$-toxin causes atopic dermatitis by promoting mast cell degranulation [75].

\section{A. Phenol-soluble modulins (PSMs)}

PSMs are a family of multifunctional peptides that exhibit cytolytic and pro-inflammatory properties during the pathogeneses of staphylococcal infections [43]. Most PSMs are encoded on the core genome, and their expressions are regulated by agr [76,77]. PSMs are classified into two subfamilies, PSM $\alpha 1-4$ and PSM $\beta 1-2$. The PSM $\alpha$ peptides PSM $\alpha 1-\alpha 4$ are encoded in the psm $\alpha$ locus [43].

Hemolysin- $\delta$ (Hld, $\delta$-toxin) is a member of the PSM $\alpha$ subfamily [53]. PSM $\alpha 1$ and PSM $\alpha 2$ have antimicrobial activities that inhibit colonization by competing pathogens [78]. PSMs trigger inflammatory responses by interacting with human formyl peptide receptor 2 (FPR2), but their cytolytic activities for red and white blood cells are FPR2independent $[77,79,80]$.

\section{Control of Toxin Expression by the agr-QS System}

Quorum sensing (QS) is a bacterial cell-to-cell communication system [11]. S. aureus invades the host with increased urgency using various virulence factors when a chemical signal that the population of $S$. aureus has reached a sufficient level is detected through the QS system, which is encoded by the agr locus [10,81]. The agr operon has two divergent promoters, P2 and P3 (Fig. 2) [82]. P2 generates RNAII, which encodes for four proteins - AgrB, AgrD, AgrC, and AgrA, whereas P3 produces RNAIII, which encodes for hemolysin- $\delta$ and small regulatory RNA molecule which regulates the expression of numerous secretory toxins such as enterotoxins, hemolysins, leukotoxins and proteases, and several cell-surface associated virulence factors such as protein A, fibronectin-binding proteins, and coagulases [76,83,84].

Autoinducing peptide (AIP) is a pheromone that induces interactions between individual staphylococcal bacteria, and its precursor is encoded on $\operatorname{AgrD}[85,86]$. S. aureus produces and accumulates AIP in the extracellular environment in response to fluctuations in cell-population density, and AIP modulates toxic gene expressions by activating the $a g r$ system when its concentration reaches a threshold [76,82]. After binding to AIP, AgrC phosphorylates AgrA, which activates $\mathrm{P} 2$ and $\mathrm{P} 3$ promoters and results in the productions of various toxins [76,82].

$A g r$-QS system exerts its various biological functions by regulating virulence factor expression, biofilm formation and antibiotic resistance, and because these functions are known to play crucial roles in the pathogenesis of S. aureus, quorum quenchers have recently emerged as attractive therapeutic agents that inhibit the virulence and control staphylococcal diseases [6-8].

\section{Anti-virulence Therapies and Natural Products}

Antibiotics are first-line treatments that inhibit the bacterial growth cycle by blocking the synthesis of essential survival factors. As conventional treatments are ineffective against infections caused by antibiotic-resistant strains such as penicillin-resistant $S$. aureus (PRSA), methicillin-resistant $S$. aureus (MRSA) or vancomycin-resistant $S$. aureus (VRSA), innovative therapeutic approaches are required [87]. Recently, anti-toxin antibodies that neutralize single virulence factors have been engineered and shown to prevent or treat staphylococcal diseases in various animal models. Monocloncal antibodies such as mAbs 7B8 and 1A9, mAb 2A3.1, mAb LTM14 and mAb Hla-F\#5, 


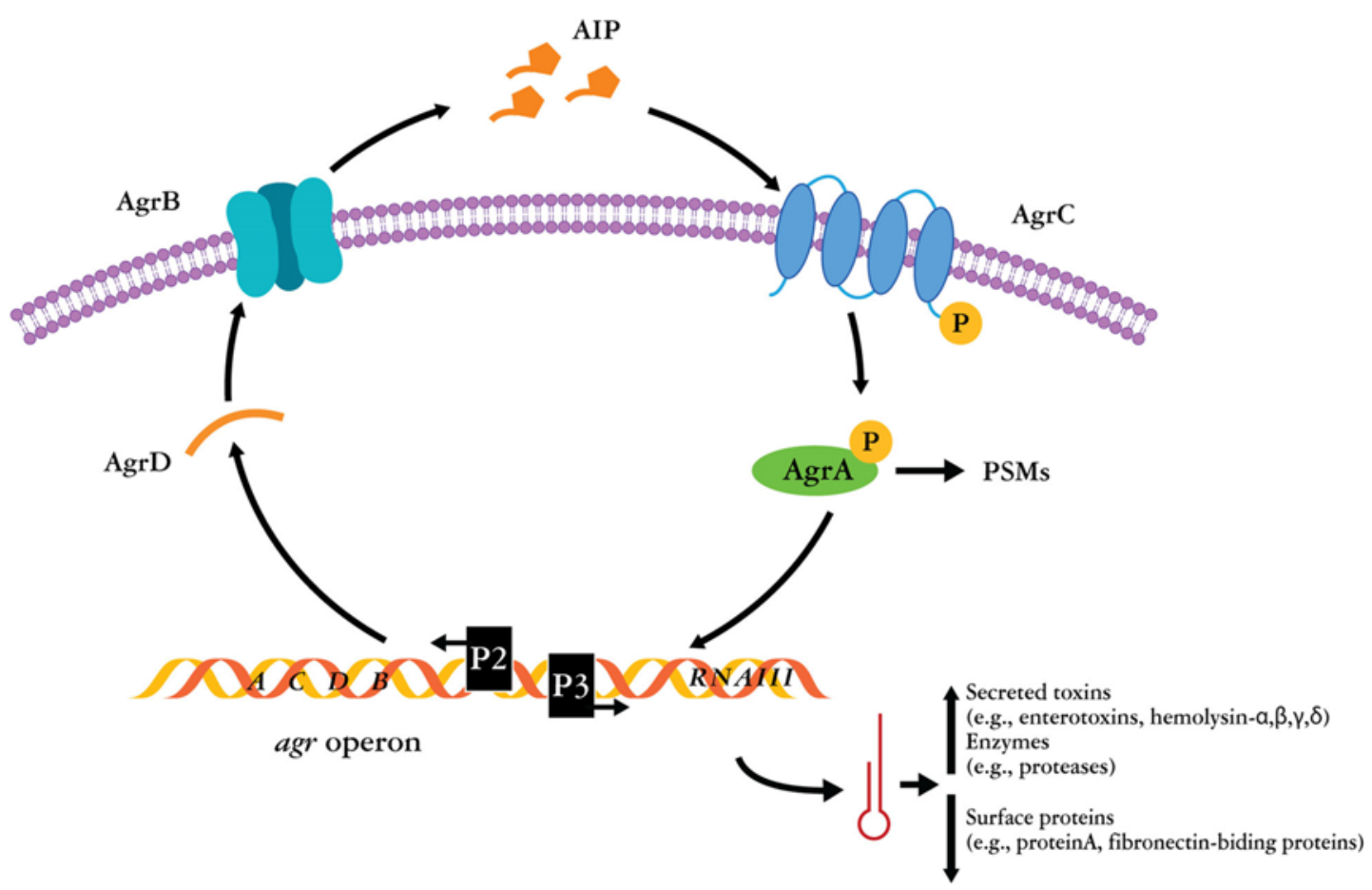

Fig. 2. Schematic diagram of the accessory gene regulator (agr) quorum-sensing (QS) system in S. aureus. S. aureus has a QS system encoded by the agr locus. The agr operon has two promoters, P2 and P3. P2 produces the RNAII transcript, which is an operon of four genes (agrA, $B, C$, and $D$ ), which encode the main components of QS. A transmembrane protein AgrB converts AgrD to autoinducing peptide (AIP) which is a ligand of another transmembrane protein AgrC, and their binding results in the autophosphorylation of AgrC. And then, AgrA is phosphorylated and activated, subsequently binds to P2 and P3, and upregulates agr transcription of RNAII and RNAIII. AgrA also induces the expressions of phenol-soluble modulins (PSMs). P3 produces the RNAIII transcript that yields small regulatory RNA molecule, which acts as the primary effector of the QS system by upregulating the productions of numerous secreted toxins and by downregulating the productions of cell-surface associated proteins. RNAIII also induces hemolysin- $\delta$ (Hld) production.

chemical compounds such as $\beta$-cyclodextrin derivatives and ADAM10 inhibitor (GI254023X), and natural compounds such as morin hydrate neutralize $\alpha$-hemolysin [88-96]. Monoclonal antibody Hla-F\#5 is anti-toxin that neutralize $\alpha$-hemolysin and bi-component leukocidins, bivalent and tetravalent anti-PVL mAbs for PVL and $\gamma$-hemolysin, and anti-LukS-mut9 for PVL and other leukotoxins, whereas huMAb-154, mAb 20B1 and soluble $\mathrm{V} \beta$ protein are anti-toxins that neutralize SEB [92,97-102]. However, as mentioned above neutralization of single virulence factor may not sufficiently protect the host from S. aureus.

Combined anti-toxin/antibiotic therapies or indirect approaches targeting the agr-QS system that governs $S$. aureus virulence might be more effective at blocking the progressions of staphylococcal diseases [9-12]. Recently, RNAIII-inhibiting heptapeptide (RIP) and sarvirin were reported to disrupt the $A g r-\mathrm{QS}$ system and reduce $S$. aureus virulence [5]. Anti-virulence compounds can interfere with virulence factors such as toxins or the agr-QS system. Because these compounds do not affect bacterial growth or viability, anti-virulence therapy is likely to reduce antibiotic resistance, and thus, holds great promise as an effective solution [13].

Natural compounds that exhibit anti-toxin properties or target the $a g r-Q S$ system could be novel therapeutic agents for $S$. aureus infections. Bioactive natural components such as staphylococcal toxin neutralizing agents (e.g., morin hydrate and oroxylin glycoside) and quorum quenchers that target the agr-QS system (e.g., isorhamnetin, chrysin, puerarin, naringenin, $\omega$-hydroxyemodin, ambuic acid, 224CF2 and 430D-F5) are summarized in Table 2.

\subsection{Natural compounds that neutralize staphylococcal toxins}

Morin hydrate (also called 2',3,4',5,7-pentahydroxyflavone) is a flavonoid found in Maclura pomifera (Osage orange), Maclura tinctoria (old fustic), and in the leaves of Psidium guajava (common guava), and was found to inhibit the self-assembly of the heptameric transmembrane pore of hemolysin- $\alpha$ in mouse model of pneumonia, and thus, to inhibit hemolytic activity $[96,103,104]$.

Three oroxylin glycosides, oroxin A (ORA), oroxin B (ORB), and oroxylin A 7-O-glucuronide (OLG) are natural 
Table 2. Natural products with possible therapeutic uses as anti-virulence agents

\begin{tabular}{llll}
\hline Name & Chemical structure & Isolation from & Mechanism of action \\
\hline Neutralizing staphylococcal toxins & $\begin{array}{l}\text { Maclura pomifera, Maclura tinctoria, } \\
\text { leaves of Psidium guajava }\end{array}$ & $\begin{array}{l}\text { Inhibits self-assembly of the } \\
\text { heptameric transmembrane pore } \\
\text { of Hla }\end{array}$ \\
\hline Morin hydrate & [96,103,104] \\
Oroxin A & $\begin{array}{l}\text { Dry mature seeds, Bignoniaceae, } \\
\text { fruits (strawberry, grapes, apples, and } \\
\text { so on) vegetables (onions and so on) }\end{array}$ & $\begin{array}{l}\text { Bind to the "stem" region of Hla } \\
\text { and restrict the conformational } \\
\text { transition of toxin from monomer } \\
\text { to oligomer }\end{array}$
\end{tabular}

Oroxin B

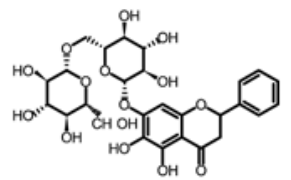

Oroxylin A

7-O-glucuronide

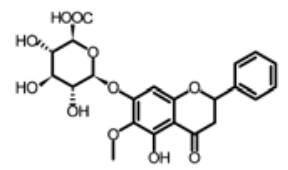

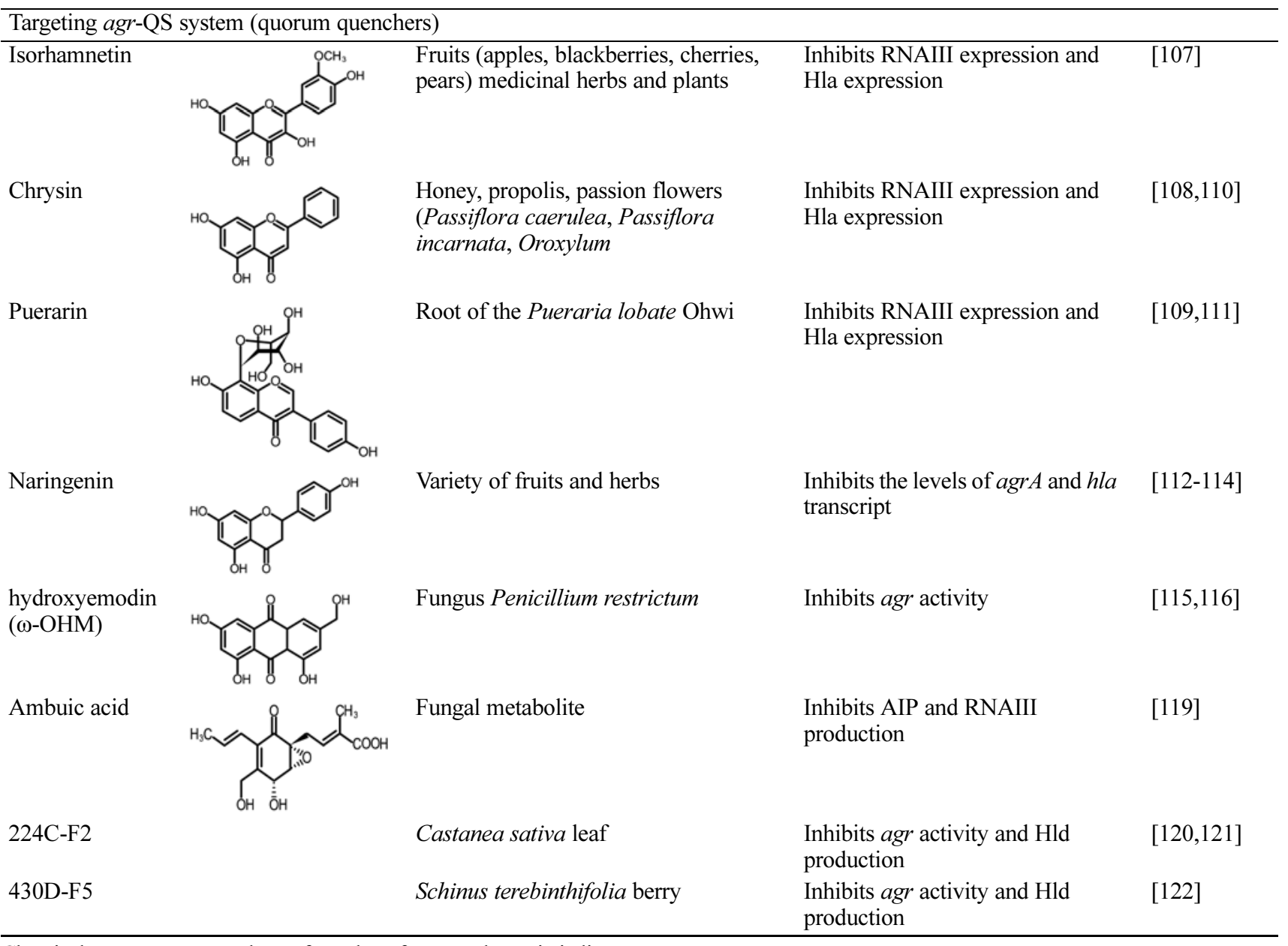

Chemical structures were redrawn from the references shown in italics.

flavonoids present in dry mature seeds, plants of the Bignoniaceae family, strawberries, grapes, apples, onions and other vegetables and fruits [105]. These compounds share structural similarity and bind to the "stem" region of 
hemolysin- $\alpha$, and by so doing, they restrict its conformational transition from monomer to oligomer in vitro and inhibit its hemolytic activity [105,106].

\subsection{Natural compounds that target the agr-QS system (quorum quenchers)}

\subsubsection{Quorum quenchers with a flavone backbone}

Isorhamnetin (also called 3'-methoxy-3,4',5,7-tetrahydroxyflavone) is a metabolite of quercetin and a naturally occurring O-methylated flavonol plentiful in apples, blackberries, cherries, pears, and in medicinal herbs and plants [107]. Chrysin (5, 7-dihydroxyflavone) is a flavone found mainly in honey, propolis, the passion flowers Passiflora caerulea and Passiflora incarnata, and Oroxylum indicum [108]. Puerarin is the major bioactive ingredient isolated from the root of Pueraria lobata Ohwi, which is well known as Gegen in traditional Chinese medicine [109]. Isorhamnetin, chrysin, and puerarin all quorum quenchers with a flavone backbone and have been reported to reduce $R N A I I I$ expression and subsequent hla expression and thus could afford protection from MRSA or MSSAprovoked pneumonia [107,110,111].

Naringenin, a predominant flavanone in grapefruit is also found in a variety of fruits and herbs, and has been reported to reduce the levels of agrA and hla transcripts significantly in $S$. aureus culture and to diminish hemolysin- $\alpha$ production and protect mice from $S$. aureusprovoked pneumonia [112-114].

\subsubsection{Quorum quenchers isolated from fungi}

Omega-hydroxyemodin ( $\omega$-OHM) isolated from Penicillium restrictum inhibited agr activity in strains expressing yellow fluorescent protein (YFP) under the control of the agr::P3 promoter [115,116]. OHM inhibits agr function by targeting AgrA binding to promoter DNA as determined by molecular docking, an electrophoretic mobility shift assay, a beadbased assay of DNA-transcription factor binding, and surface plasmon resonance. Furthermore, in a mouse model of MRSA skin infection, OHM specifically disrupted agr signaling without directly effecting the host $[12,117,118]$.

Ambuic acid is a fungal metabolite that targets AgrB, and has been reported to inhibit AIP production in S. aureus as determined by mass spectroscopy [119]. It was also reported to inhibit hemolysin- $\alpha$ production by MRSA and RNAIII production by Western blotting and quantitative real-time PCR, respectively, which indicated it repressed the $a g r-\mathrm{QS}$ system. Furthermore, in a murine mouse model of MRSA skin, a single 25g prophylactic dose of ambuic acid almost completely prevented skin ulcer formation over the course of the 14-day experiment $[12,119]$.

\subsubsection{Quorum quenchers isolated from plants}

Castanea sativa leaf extract 224C-F2 was reported to inhibit $a g r$ expression and thus, to reduce hemolysin- $\delta$ production, as determined by high-performance liquid chromatography (HPLC), and red blood cell lysis [120]. Furthermore, in an in vivo model of MRSA infection, pretreatment with 224CF2 reduced infection-induced ulcer areas and significantly attenuated morbidity [12,120,121].

Schinus terebinthifolia berry extract 430D-F5 was also found to inhibit agr expression and significantly reduce hemolysin- $\delta$ production and hemolytic activity in vitro, and in a mouse model of MRSA skin infection, pretreatment with a single $50 \mathrm{~g}$ dose of 430D-F5 reduced skin ulcer formation markedly and significantly reduced morbidity $[12,122]$.

\section{Conclusion}

$S$. aureus produces toxins that cause a wide variety of diseases in humans, for example, SEs cause SFP, and TSST- 1 causes TSS, ETs cause SSSS and cytotoxins such as hemolysins, leukotoxins, and PSMs cause cell lysis. The $A g r$-QS system controls the expressions of virulence factors and biofilm formation, and in order to eliminate antibiotic resistance caused by biofilm formation, alternative therapeutic drugs are urgently needed. Anti-virulence agents can inhibit the activities of virulence factors and pathways that mediate virulence. Recently, anti-virulence therapy has attracted considerable interest, and natural products with anti-toxin properties or that target the $a g r-\mathrm{QS}$ system have been shown to inhibit $S$. aureus virulence and control staphylococcal diseases without affecting bacterial growth or viability. For this reason, natural product-based antivirulence therapies offer the possibility of blocking the progression of staphylococcal diseases without developing antibiotic resistance. Although the molecular mechanisms responsible for the activities of these natural compounds have yet to be determined, these compounds provide starting points for the development of novel anti-virulence agents that target $S$. aureus.

\section{Acknowledgements}

The author greatly appreciates the graphic assistance provided by Byung-Ho Ko of Department of Digital Contents, Keimyung College University. This work was supported by a grant from the National Research Foundation of Korea (\#NRF-2018R1C1B5046981). 


\section{References}

1. Thammavongsa, V., H. K. Kim, D. Missiakas, and O. Schneewind (2015) Staphylococcal manipulation of host immune responses. Nat. Rev. Microbiol. 13: 529-543.

2. McAdow, M., A. C. DeDent, C. Emolo, A. G. Cheng, B. N. Kreiswirth, D. M. Missiakas, and O. Schneewind (2012) Coagulases as determinants of protective immune responses against Staphylococcus aureus. Infect. Immun. 80: 3389-3398.

3. Jusko, M., J. Potempa, T. Kantyka, E. Bielecka, H. K. Miller, M. Kalinska, G. Dubin, P. Garred, L. N. Shaw, and A. M. Blom (2014) Staphylococcal proteases aid in evasion of the human complement system. J. Innate Immun. 6: 31-46.

4. Foster, T. J., J. A. Geoghegan, V. K. Ganesh, and M. Hook (2014) Adhesion, invasion and evasion: the many functions of the surface proteins of Staphylococcus aureus. Nat. Rev. Microbiol. 12: 49-62.

5. Kong, C., H. M. Neoh, and S. Nathan (2016) Targeting Staphylococcus aureus toxins: a potential form of anti-virulence therapy. Toxins (Basel). 8: 10.3390/toxins8030072.

6. Singh, R. and P. Ray (2014) Quorum sensing-mediated regulation of staphylococcal virulence and antibiotic resistance. Future Microbiol. 9: 669-681.

7. Mohsenzadeh, M., K. Ghazvini, and A. Azimian (2015) Frequency of specific agr groups and antibiotic resistance in Staphylococcus aureus isolated from bovine mastitis in the northeast of Iran. Vet. Res. Forum. 6: 295-299.

8. Kavanaugh, J. S. and A. R. Horswill (2016) Impact of environmental cues on staphylococcal quorum sensing and biofilm development. J. Biol. Chem. 291: 12556-12564.

9. Bagnoli, F. (2017) Staphylococcus aureus toxin antibodies: good companions of antibiotics and vaccines. Virulence. 8: 1037-1042.

10. Zhang, X., M. H. Marichannegowda, K. P. Rakesh, and H. L. Qin (2018) Master mechanisms of Staphylococcus aureus: consider its excellent protective mechanisms hindering vaccine development! Microbiol. Res. 212-213: 59-66.

11. Tan, L., S. R. Li, B. Jiang, X. M. Hu, and S. Li (2018) Therapeutic targeting of the Staphylococcus aureus accessory gene regulator (agr) system. Front. Microbiol. 9: 55.

12. Salam, A. M. and C. L. Quave (2018) Targeting Virulence in Staphylococcus aureus by chemical inhibition of the accessory gene regulator system in vivo. mSphere. 3: $10.1128 / \mathrm{mSphere}$. 00500-17.

13. Rasko, D. A. and V. Sperandio (2010) Anti-virulence strategies to combat bacteria-mediated disease. Nat. Rev. Drug Discov. 9: $117-128$.

14. Dinges, M. M., P. M. Orwin, and P. M. Schlievert (2000) Exotoxins of Staphylococcus aureus. Clin. Microbiol. Rev. 13: 16-34.

15. Holtfreter, S. and B. M. Broker (2005) Staphylococcal superantigens: do they play a role in sepsis? Arch. Immunol. Ther. Exp. (Warsz). 53: 13-27.

16. Ladhani, S. (2003) Understanding the mechanism of action of the exfoliative toxins of Staphylococcus aureus. FEMS Immunol. Med. Microbiol. 39: 181-189.

17. Lina, G., G. A. Bohach, S. P. Nair, K. Hiramatsu, E. JouvinMarche, R. Mariuzza, and International Nomenclature Committee for Staphylococcal Superantigens (2004) Standard nomenclature for the superantigens expressed by Staphylococcus. J. Infect. Dis. 189: 2334-2336.

18. Wilson, G. J., K. S. Seo, R. A. Cartwright, T. Connelley, O. N. Chuang-Smith, J. A. Merriman, C. M. Guinane, J. Y. Park, G. A. Bohach, P. M. Schlievert, W. I. Morrison, and J. R. Fitzgerald (2011) A novel core genome-encoded superantigen contributes to lethality of community-associated MRSA necrotizing pneumonia. PLoS Pathog. 7: e1002271.

19. Lindsay, J. A. and M. T. Holden (2006) Understanding the rise of the superbug: investigation of the evolution and genomic variation of Staphylococcus aureus. Funct. Integr. Genomics. 6: 186-201.

20. Ono, H. K., K. Omoe, K. Imanishi, Y. Iwakabe, D. L. Hu, H. Kato, N. Saito, A. Nakane, T. Uchiyama, and K. Shinagawa (2008) Identification and characterization of two novel staphylococcal enterotoxins, types S and T. Infect. Immun. 76: 4999-5005.

21. Andrey, D. O., A. Renzoni, A. Monod, D. P. Lew, A. L. Cheung, and W. L. Kelley (2010) Control of the Staphylococcus aureus toxic shock tst promoter by the global regulator SarA. J. Bacteriol. 192: 6077-6085.

22. Kusch, K., K. Hanke, S. Holtfreter, M. Schmudde, C. Kohler, C. Erck, J. Wehland, M. Hecker, K. Ohlsen, B. Broker, and S. Engelmann (2011) The influence of SaeRS and sigma (B) on the expression of superantigens in different Staphylococcus aureus isolates. Int. J. Med. Microbiol. 301: 488-499.

23. Tseng, C. W., S. Zhang, and G. C. Stewart (2004) Accessory gene regulator control of staphyloccoccal enterotoxin $\mathrm{d}$ gene expression. J. Bacteriol. 186: 1793-1801.

24. Wieczorek, M., E. T. Abualrous, J. Sticht, M. Alvaro-Benito, S. Stolzenberg, F. Noe, and C. Freund (2017) Major histocompatibility complex (MHC) class I and MHC class II proteins: conformational plasticity in antigen presentation. Front. Immunol. 8: 292.

25. Fraser, J. D. and T. Proft (2008) The bacterial superantigen and superantigen-like proteins. Immunol. Rev. 225: 226-243.

26. Proft, T. and J. D. Fraser (2003) Bacterial superantigens. Clin. Exp. Immunol. 133: 299-306.

27. Larkin, S. M., D. N. Williams, M. T. Osterholm, R. W. Tofte, and Z. Posalaky (1982) Toxic shock syndrome: clinical, laboratory, and pathologic findings in nine fatal cases. Ann. Intern. Med. 96: 858-864.

28. Araake, M., T. Uchiyama, K. Imanishi, and X. J. Yan (1991) Activation of human vascular endothelial cells by IFN-gamma: acquisition of HLA class II expression, TSST-1-binding activity and accessory activity in T cell activation by the toxin. Int. Arch. Allergy Appl. Immunol. 96: 55-61.

29. Krakauer, T. (1994) Cell adhesion molecules are co-receptors for staphylococcal enterotoxin B-induced T-cell activation and cytokine production. Immunol. Lett. 39: 121-125.

30. Uchiyama, T., M. Araake, X. J. Yan, Y. Miyanaga, and H. Igarashi (1992) Involvement of HLA class II molecules in acquisition of staphylococcal enterotoxin A-binding activity and accessory cell activity in activation of human T cells by related toxins in vascular endothelial cells. Clin. Exp. Immunol. 87: 322-328.

31. Kotzin, B. L., D. Y. Leung, J. Kappler, and P. Marrack (1993) Superantigens and their potential role in human disease. $A d v$. Immunol. 54: 99-166.

32. Geoghegan, J. A., A. D. Irvine, and T. J. Foster (2018) Staphylococcus aureus and atopic dermatitis: a complex and evolving relationship. Trends Microbiol. 26: 484-497

33. Hennekinne, J. A., M. L. De Buyser, and S. Dragacci (2012) Staphylococcus aureus and its food poisoning toxins: characterization and outbreak investigation. FEMS Microbiol. Rev. 36: 815-836.

34. Otto, M. (2014) Staphylococcus aureus toxins. Curr. Opin. Microbiol. 17: 32-37.

35. Thomas, D., S. Chou, O. Dauwalder, and G. Lina (2007) Diversity in Staphylococcus aureus enterotoxins. Chem. Immunol. Allergy. 93: 24-41.

36. Kent, T. H. (1966) Staphylococcal enterotoxin gastroenteritis in 
rhesus monkeys. Am. J. Pathol. 48: 387-407.

37. Zapor, M. and J. T. Fishbain (2004) Aerosolized biologic toxins as agents of warfare and terrorism. Respir. Care Clin. N. Am. 10: 111-122.

38. Salgado-Pabon, W., L. Breshears, A. R. Spaulding, J. A. Merriman, C. S. Stach, A. R. Horswill, M. L. Peterson, and P. M. Schlievert (2013) Superantigens are critical for Staphylococcus aureus infective endocarditis, sepsis, and acute kidney injury. MBio. 4: 10.1128/mBio.00494-13.

39. Stach, C. S., A. Herrera, and P. M. Schlievert (2014) Staphylococcal superantigens interact with multiple host receptors to cause serious diseases. Immunol. Res. 59: 177-181.

40. Bergdoll, M. S., B. A. Crass, R. F. Reiser, R. N. Robbins, and J. P. Davis (1981) A new staphylococcal enterotoxin, enterotoxin F, associated with toxic-shock-syndrome Staphylococcus aureus isolates. Lancet. 1: 1017-1021.

41. McCormick, J. K., J. M. Yarwood, and P. M. Schlievert (2001) Toxic shock syndrome and bacterial superantigens: an update. Annu. Rev. Microbiol. 55: 77-104.

42. Rellahan, B. L., L. A. Jones, A. M. Kruisbeek, A. M. Fry, and L. A. Matis (1990) In vivo induction of anergy in peripheral $\mathrm{V}$ beta 8+ T cells by staphylococcal enterotoxin B. J. Exp. Med. 172: 1091-1100.

43. Grumann, D., U. Nubel, and B. M. Broker (2014) Staphylococcus aureus toxins--their functions and genetics. Infect. Genet. Evol. 21: $583-592$.

44. Alderson, M. R., T. W. Tough, T. Davis-Smith, S. Braddy, B. Falk, K. A. Schooley, R. G. Goodwin, C. A. Smith, F. Ramsdell, and D. H. Lynch (1995) Fas ligand mediates activation-induced cell death in human T lymphocytes. J. Exp. Med. 181: 71-77.

45. Fraser, J., V. Arcus, P. Kong, E. Baker, and T. Proft (2000) Superantigens - powerful modifiers of the immune system. Mol. Med. Today. 6: 125-132.

46. Reingold, A. L., N. T. Hargrett, B. B. Dan, K. N. Shands, B. Y. Strickland, and C. V. Broome (1982) Nonmenstrual toxic shock syndrome: a review of 130 cases. Ann. Intern. Med. 96: 871874.

47. Leist, M., F. Gantner, I. Bohlinger, P. G. Germann, G. Tiegs, and A. Wendel (1994) Murine hepatocyte apoptosis induced in vitro and in vivo by TNF-alpha requires transcriptional arrest. $J$. Immunol. 153: 1778-1788.

48. Sheehan, B. J., T. J. Foster, C. J. Dorman, S. Park, and G. S. Stewart (1992) Osmotic and growth-phase dependent regulation of the eta gene of Staphylococcus aureus: a role for DNA supercoiling. Mol. Gen. Genet. 232: 49-57.

49. Eyre, R. W. and J. R. Stanley (1987) Human autoantibodies against a desmosomal protein complex with a calcium-sensitive epitope are characteristic of pemphigus foliaceus patients. $J$. Exp. Med. 165: 1719-1724.

50. Hanakawa, Y., N. M. Schechter, C. Lin, L. Garza, H. Li, T. Yamaguchi, Y. Fudaba, K. Nishifuji, M. Sugai, M. Amagai, and J. R. Stanley (2002) Molecular mechanisms of blister formation in bullous impetigo and staphylococcal scalded skin syndrome. J. Clin. Invest. 110: 53-60.

51. Nishifuji, K., M. Sugai, and M. Amagai (2008) Staphylococcal exfoliative toxins: "molecular scissors" of bacteria that attack the cutaneous defense barrier in mammals. J. Dermatol. Sci. 49: 21-31.

52. Bukowski, M., B. Wladyka, and G. Dubin (2010) Exfoliative toxins of Staphylococcus aureus. Toxins (Basel). 2: 1148-1165.

53. Yoshida, A. (1963) Staphylococcal delta-hemolysin. I. Purification and chemical properties. Biochim. Biophys. Acta. 71: 544-553.

54. Xiong, Y. Q., J. Willard, M. R. Yeaman, A. L. Cheung, and A. S. Bayer (2006) Regulation of Staphylococcus aureus alphatoxin gene (hla) expression by agr, sarA, and sae in vitro and in experimental infective endocarditis. J. Infect. Dis. 194: 1267-
1275.

55. Inoshima, I., N. Inoshima, G. A. Wilke, M. E. Powers, K. M. Frank, Y. Wang, and J. Bubeck Wardenburg (2011) A Staphylococcus aureus pore-forming toxin subverts the activity of ADAM10 to cause lethal infection in mice. Nat. Med. 17: 1310-1314.

56. Wilke, G. A. and J. Bubeck Wardenburg (2010) Role of a disintegrin and metalloprotease 10 in Staphylococcus aureus alpha-hemolysin-mediated cellular injury. Proc. Natl. Acad. Sci. U. S. A. 107: 13473-13478.

57. Valeva, A., I. Walev, M. Pinkernell, B. Walker, H. Bayley, M. Palmer, and S. Bhakdi (1997) Transmembrane beta-barrel of staphylococcal alpha-toxin forms in sensitive but not in resistant cells. Proc. Natl. Acad. Sci. U. S. A. 94: 11607-11611.

58. Walev, I., U. Weller, S. Strauch, T. Foster, and S. Bhakdi (1996) Selective killing of human monocytes and cytokine release provoked by sphingomyelinase (beta-toxin) of Staphylococcus aureus. Infect. Immun. 64: 2974-2979.

59. Green, D. R. (2000) Apoptosis and sphingomyelin hydrolysis. The flip side. J. Cell Biol. 150: F5-7.

60. Olson, R., H. Nariya, K. Yokota, Y. Kamio, and E. Gouaux (1999) Crystal structure of staphylococcal LukF delineates conformational changes accompanying formation of a transmembrane channel. Nat. Struct. Biol. 6: 134-140.

61. Meyer, F., R. Girardot, Y. Piemont, G. Prevost, and D. A. Colin (2009) Analysis of the specificity of Panton-Valentine leucocidin and gamma-hemolysin F component binding. Infect. Immun. 77: 266-273.

62. Vandenesch, F., G. Lina, and T. Henry (2012) Staphylococcus aureus hemolysins, bi-component leukocidins, and cytolytic peptides: a redundant arsenal of membrane-damaging virulence factors? Front. Cell. Infect. Microbiol. 2: 12.

63. Kaneko, J. and Y. Kamio (2004) Bacterial two-component and hetero-heptameric pore-forming cytolytic toxins: structures, pore-forming mechanism, and organization of the genes. Biosci. Biotechnol. Biochem. 68: 981-1003.

64. Dumont, A. L., T. K. Nygaard, R. L. Watkins, A. Smith, L. Kozhaya, B. N. Kreiswirth, B. Shopsin, D. Unutmaz, J. M. Voyich, and V. J. Torres (2011) Characterization of a new cytotoxin that contributes to Staphylococcus aureus pathogenesis. Mol. Microbiol. 79: 814-825.

65. Morinaga, N., Y. Kaihou, and M. Noda (2003) Purification, cloning and characterization of variant LukE-LukD with strong leukocidal activity of staphylococcal bi-component leukotoxin family. Microbiol. Immunol. 47: 81-90.

66. Prevost, G., L. Mourey, D. A. Colin, and G. Menestrina (2001) Staphylococcal pore-forming toxins. Curr. Top. Microbiol. Immunol. 257: 53-83.

67. Ventura, C. L., N. Malachowa, C. H. Hammer, G. A. Nardone, M. A. Robinson, S. D. Kobayashi, and F. R. DeLeo (2010) Identification of a novel Staphylococcus aureus two-component leukotoxin using cell surface proteomics. PLoS One. 5: e11634.

68. DuMont, A. L., P. Yoong, B. G. Surewaard, M. A. Benson, R. Nijland, J. A. van Strijp, and V. J. Torres (2013) Staphylococcus aureus elaborates leukocidin $\mathrm{AB}$ to mediate escape from within human neutrophils. Infect. Immun. 81: 1830-1841.

69. Kaneko, J., T. Kimura, S. Narita, T. Tomita, and Y. Kamio (1998) Complete nucleotide sequence and molecular characterization of the temperate staphylococcal bacteriophage phiPVL carrying Panton-Valentine leukocidin genes. Gene. 215: 57-67.

70. Narita, S., J. Kaneko, J. Chiba, Y. Piemont, S. Jarraud, J. Etienne, and Y. Kamio (2001) Phage conversion of PantonValentine leukocidin in Staphylococcus aureus: molecular analysis of a PVL-converting phage, phiSLT. Gene. 268: 195206.

71. Alonzo, F.,3rd, L. Kozhaya, S. A. Rawlings, T. Reyes-Robles, 
A. L. DuMont, D. G. Myszka, N. R. Landau, D. Unutmaz, and V. J. Torres (2013) CCR5 is a receptor for Staphylococcus aureus leukotoxin ED. Nature. 493: 51-55.

72. DuMont, A. L., P. Yoong, C. J. Day, F. Alonzo 3rd, W. H. McDonald, M. P. Jennings, and V. J. Torres (2013) Staphylococcus aureus LukAB cytotoxin kills human neutrophils by targeting the CD11b subunit of the integrin Mac-1. Proc. Natl. Acad. Sci. U. S. A. 110: 10794-10799.

73. Spaan, A. N., T. Henry, W. J. van Rooijen, M. Perret, C. Badiou, P. C. Aerts, J. Kemmink, C. J. de Haas, K. P. van Kessel, F. Vandenesch, G. Lina, and J. A. van Strijp (2013) The staphylococcal toxin Panton-Valentine Leukocidin targets human C5a receptors. Cell. Host Microbe. 13: 584-594.

74. Gillet, Y., B. Issartel, P. Vanhems, J. C. Fournet, G. Lina, M. Bes, F. Vandenesch, Y. Piemont, N. Brousse, D. Floret, and J. Etienne (2002) Association between Staphylococcus aureus strains carrying gene for Panton-Valentine leukocidin and highly lethal necrotising pneumonia in young immunocompetent patients. Lancet. 359: 753-759.

75. Nakamura, Y., J. Oscherwitz, K. B. Cease, S. M. Chan, R. Munoz-Planillo, M. Hasegawa, A. E. Villaruz, G. Y. Cheung, M. J. McGavin, J. B. Travers, M. Otto, N. Inohara, and G. Nunez (2013) Staphylococcus delta-toxin induces allergic skin disease by activating mast cells. Nature. 503: 397-401.

76. Queck, S. Y., M. Jameson-Lee, A. E. Villaruz, T. H. Bach, B. A. Khan, D. E. Sturdevant, S. M. Ricklefs, M. Li, and M. Otto (2008) RNAIII-independent target gene control by the agr quorum-sensing system: insight into the evolution of virulence regulation in Staphylococcus aureus. Mol. Cell. 32: 150-158.

77. Wang, R., K. R. Braughton, D. Kretschmer, T. H. Bach, S. Y. Queck, M. Li, A. D. Kennedy, D. W. Dorward, S. J. Klebanoff, A. Peschel, F. R. DeLeo, and M. Otto (2007) Identification of novel cytolytic peptides as key virulence determinants for community-associated MRSA. Nat. Med. 13: 1510-1514.

78. Joo, H. S., G. Y. Cheung, and M. Otto (2011) Antimicrobial activity of community-associated methicillin-resistant Staphylococcus aureus is caused by phenol-soluble modulin derivatives. J. Biol. Chem. 286: 8933-8940.

79. Kretschmer, D., A. K. Gleske, M. Rautenberg, R. Wang, M. Koberle, E. Bohn, T. Schoneberg, M. J. Rabiet, F. Boulay, S. J. Klebanoff, K. A. van Kessel, J. A. van Strijp, M. Otto, and A. Peschel (2010) Human formyl peptide receptor 2 senses highly pathogenic Staphylococcus aureus. Cell. Host Microbe. 7: 463473.

80. Cheung, G. Y., K. Rigby, R. Wang, S. Y. Queck, K. R. Braughton, A. R. Whitney, M. Teintze, F. R. DeLeo, and M. Otto (2010) Staphylococcus epidermidis strategies to avoid killing by human neutrophils. PLoS Pathog. 6: e1001133.

81. Fuqua, W. C., S. C. Winans, and E. P. Greenberg (1994) Quorum sensing in bacteria: the LuxR-LuxI family of cell density-responsive transcriptional regulators. J. Bacteriol. 176: 269-275.

82. Ji, G., R. C. Beavis, and R. P. Novick (1995) Cell density control of staphylococcal virulence mediated by an octapeptide pheromone. Proc. Natl. Acad. Sci. U. S. A. 92: 12055-12059.

83. Novick, R. P. and E. Geisinger (2008) Quorum sensing in staphylococci. Annu. Rev. Genet. 42: 541-564.

84. Arya, R. and S. A. Princy (2016) Exploration of modulated genetic circuits governing virulence determinants in Staphylococcus aureus. Indian J. Microbiol. 56: 19-27.

85. Khan, B. A., A. J. Yeh, G. Y. Cheung, and M. Otto (2015) Investigational therapies targeting quorum-sensing for the treatment of Staphylococcus aureus infections. Expert Opin. Investig. Drugs. 24: 689-704.

86. Novick, R. P. (2003) Autoinduction and signal transduction in the regulation of staphylococcal virulence. Mol. Microbiol. 48:
1429-1449.

87. Lee, D., Y. Seo, M. S. Khan, J. Hwang, Y. Jo, J. Son, K. Lee, C. Park, S. Chavan, and A. A. Gilad (2018) Use of nanoscale materials for the effective prevention and extermination of bacterial biofilms. Biotechnol. Bioproc. Eng. 23: 1-10.

88. Ragle, B. E. and J. Bubeck Wardenburg (2009) Anti-alphahemolysin monoclonal antibodies mediate protection against Staphylococcus aureus pneumonia. Infect. Immun. 77: 27122718.

89. Hua, L., J. J. Hilliard, Y. Shi, C. Tkaczyk, L. I. Cheng, X. Yu, V. Datta, S. Ren, H. Feng, R. Zinsou, A. Keller, T. O’Day, Q. Du, L. Cheng, M. Damschroder, G. Robbie, J. Suzich, C. K. Stover, and B. R. Sellman (2014) Assessment of an anti-alpha-toxin monoclonal antibody for prevention and treatment of Staphylococcus aureus-induced pneumonia. Antimicrob. Agents Chemother. 58: 1108-1117.

90. Tkaczyk, C., L. Hua, R. Varkey, Y. Shi, L. Dettinger, R. Woods, A. Barnes, R. S. MacGill, S. Wilson, P. Chowdhury, C. K. Stover, and B. R. Sellman (2012) Identification of anti-alpha toxin monoclonal antibodies that reduce the severity of Staphylococcus aureus dermonecrosis and exhibit a correlation between affinity and potency. Clin. Vaccine Immunol. 19: 377385.

91. Foletti, D., P. Strop, L. Shaughnessy, A. Hasa-Moreno, M. G. Casas, M. Russell, C. Bee, S. Wu, A. Pham, Z. Zeng, J. Pons, A. Rajpal, and D. Shelton (2013) Mechanism of action and in vivo efficacy of a human-derived antibody against Staphylococcus aureus alpha-hemolysin. J. Mol. Biol. 425: 1641-1654.

92. Rouha, H., A. Badarau, Z. C. Visram, M. B. Battles, B. Prinz, Z. Magyarics, G. Nagy, I. Mirkina, L. Stulik, M. Zerbs, M. Jagerhofer, B. Maierhofer, A. Teubenbacher, I. Dolezilkova, K. Gross, S. Banerjee, G. Zauner, S. Malafa, J. Zmajkovic, S. Maier, R. Mabry, E. Krauland, K. D. Wittrup, T. U. Gerngross, and E. Nagy (2015) Five birds, one stone: neutralization of alpha-hemolysin and 4 bi-component leukocidins of Staphylococcus aureus with a single human monoclonal antibody. MAbs. 7: 243-254.

93. Karginov, V. A., E. M. Nestorovich, F. Schmidtmann, T. M. Robinson, A. Yohannes, N. E. Fahmi, S. M. Bezrukov, and S. M. Hecht (2007) Inhibition of S. aureus alpha-hemolysin and B. anthracis lethal toxin by beta-cyclodextrin derivatives. Bioorg. Med. Chem. 15: 5424-5431.

94. Ragle, B. E., V. A. Karginov, and J. Bubeck Wardenburg (2010) Prevention and treatment of Staphylococcus aureus pneumonia with a beta-cyclodextrin derivative. Antimicrob. Agents Chemother. 54: 298-304.

95. Sampedro, G. R., A. C. DeDent, R. E. Becker, B. J. Berube, M. J. Gebhardt, H. Cao, and J. Bubeck Wardenburg (2014) Targeting Staphylococcus aureus alpha-toxin as a novel approach to reduce severity of recurrent skin and soft-tissue infections. J. Infect. Dis. 210: 1012-1018.

96. Wang, J., X. Zhou, S. Liu, G. Li, L. Shi, J. Dong, W. Li, X. Deng, and X. Niu (2015) Morin hydrate attenuates Staphylococcus aureus virulence by inhibiting the self-assembly of alpha-hemolysin. J. Appl. Microbiol. 118: 753-763.

97. Laventie, B. J., H. J. Rademaker, M. Saleh, E. de Boer, R. Janssens, T. Bourcier, A. Subilia, L. Marcellin, R. van Haperen, J. H. Lebbink, T. Chen, G. Prevost, F. Grosveld, and D. Drabek (2011) Heavy chain-only antibodies and tetravalent bispecific antibody neutralizing Staphylococcus aureus leukotoxins. Proc. Natl. Acad. Sci. U. S. A. 108: 16404-16409.

98. Adhikari, R. P., T. Kort, S. Shulenin, T. Kanipakala, N. Ganjbaksh, M. C. Roghmann, F. W. Holtsberg, and M. J. Aman (2015) Antibodies to $S$. aureus LukS-PV attenuated subunit vaccine neutralize a broad spectrum of canonical and noncanonical bicomponent leukotoxin pairs. PLoS One. 10: 
e0137874.

99. Drozdowski, B., Y. Zhou, B. Kline, J. Spidel, Y. Y. Chan, E. Albone, H. Turchin, Q. Chao, M. Henry, J. Balogach, E. Routhier, S. Bavari, N. C. Nicolaides, P. M. Sass, and L. Grasso (2010) Generation and characterization of high affinity human monoclonal antibodies that neutralize staphylococcal enterotoxin B. J. Immune Based. Ther. Vaccines. 8: 9.

100. Dutta, K., A. K. Varshney, M. C. Franklin, M. Goger, X. Wang, and B. C. Fries (2015) Mechanisms mediating enhanced neutralization efficacy of staphylococcal enterotoxin B by combinations of monoclonal antibodies. J. Biol. Chem. 290: 6715-6730.

101. Varshney, A. K., X. Wang, M. D. Scharff, J. MacIntyre, R. S. Zollner, O. V. Kovalenko, L. R. Martinez, F. R. Byrne, and B. C. Fries (2013) Staphylococcal enterotoxin B-specific monoclonal antibody 20B1 successfully treats diverse Staphylococcus aureus infections. J. Infect. Dis. 208: 2058-2066.

102. Buonpane, R. A., H. R. Churchill, B. Moza, E. J. Sundberg, M. L. Peterson, P. M. Schlievert, and D. M. Kranz (2007) Neutralization of staphylococcal enterotoxin B by soluble, highaffinity receptor antagonists. Nat. Med. 13: 725-729.

103. Patel, P., K. Parmar, and M. Das (2018) Inhibition of insulin amyloid fibrillation by Morin hydrate. Int. J. Biol. Macromol. 108: 225-239.

104. Rattanachaikunsopon, P. and P. Phumkhachorn (2007) Bacteriostatic effect of flavonoids isolated from leaves of Psidium guajava on fish pathogens. Fitoterapia. 78: 434-436.

105. Qiu, J., D. Wang, Y. Zhang, J. Dong, J. Wang, and X. Niu (2013) Molecular modeling reveals the novel inhibition mechanism and binding mode of three natural compounds to staphylococcal alpha-hemolysin. PLoS One. 8: e80197.

106. Dong, J., J. Qiu, Y. Zhang, C. Lu, X. Dai, J. Wang, H. Li, X. Wang, W. Tan, M. Luo, X. Niu, and X. Deng (2013) Oroxylin A inhibits hemolysis via hindering the self-assembly of alphahemolysin heptameric transmembrane pore. PLoS Comput. Biol. 9: e1002869.

107. Jiang, L., H. Li, L. Wang, Z. Song, L. Shi, W. Li, X. Deng, and J. Wang (2016) Isorhamnetin attenuates Staphylococcus aureusinduced lung cell injury by inhibiting alpha-hemolysin expression. J. Microbiol. Biotechnol. 26: 596-602.

108. Nabavi, S. F., N. Braidy, S. Habtemariam, I. E. Orhan, M. Daglia, A. Manayi, O. Gortzi, and S. M. Nabavi (2015) Neuroprotective effects of chrysin: From chemistry to medicine. Neurochem. Int. 90: 224-231.

109. Zhou, Y. X., H. Zhang, and C. Peng (2014) Puerarin: a review of pharmacological effects. Phytother. Res. 28: 961-975.

110. Wang, J., J. Qiu, J. Dong, H. Li, M. Luo, X. Dai, Y. Zhang, B. Leng, X. Niu, S. Zhao, and X. Deng (2011) Chrysin protects mice from Staphylococcus aureus pneumonia. J. Appl. Microbiol. 111: 1551-1558.

111. Tang, F., W. H. Li, X. Zhou, Y. H. Liu, Z. Li, Y. S. Tang, X. Kou, S. D. Wang, M. Bao, L. D. Qu, M. Li, and B. Li (2014) Puerarin protects against Staphylococcus aureus-induced injury of human alveolar epithelial A549 cells via downregulating alpha-hemolysin secretion. Microb. Drug Resist. 20: 357-363.

112. Khan, A. W., S. Kotta, S. H. Ansari, R. K. Sharma, and J. Ali (2015) Self-nanoemulsifying drug delivery system (SNEDDS) of the poorly water-soluble grapefruit flavonoid Naringenin: design, characterization, in vitro and in vivo evaluation. Drug Deliv. 22: 552-561.

113. Salehi, B., P. V. T. Fokou, M. Sharifi-Rad, P. Zucca, R. Pezzani, N. Martins, and J. Sharifi-Rad (2019) The therapeutic potential of naringenin: a review of clinical trials. Pharmaceuticals (Basel). 12: 10.3390/ph12010011.

114. Zhang, Y., J. F. Wang, J. Dong, J. Y. Wei, Y. N. Wang, X. H. Dai, X. Wang, M. J. Luo, W. Tan, X. M. Deng, and X. D. Niu (2013) Inhibition of alpha-toxin production by subinhibitory concentrations of naringenin controls Staphylococcus aureus pneumonia. Fitoterapia. 86: 92-99.

115. Figueroa, M., A. K. Jarmusch, H. A. Raja, T. El-Elimat, J. S. Kavanaugh, A. R. Horswill, R. G. Cooks, N. B. Cech, and N. H. Oberlies (2014) Polyhydroxyanthraquinones as quorum sensing inhibitors from the guttates of Penicillium restrictum and their analysis by desorption electrospray ionization mass spectrometry. J. Nat. Prod. 77: 1351-1358.

116. Daly, S. M., B. O. Elmore, J. S. Kavanaugh, K. D. Triplett, M. Figueroa, H. A. Raja, T. El-Elimat, H. A. Crosby, J. K. Femling, N. B. Cech, A. R. Horswill, N. H. Oberlies, and P. R. Hall (2015) omega-Hydroxyemodin limits Staphylococcus aureus quorum sensing-mediated pathogenesis and inflammation. Antimicrob. Agents Chemother. 59: 2223-2235.

117. Geisinger, E., T. W. Muir, and R. P. Novick (2009) Agr receptor mutants reveal distinct modes of inhibition by staphylococcal autoinducing peptides. Proc. Natl. Acad. Sci. U. S. A. 106: 1216-1221.

118. Malachowa, N., S. D. Kobayashi, K. R. Braughton, and F. R. DeLeo (2013) Mouse model of Staphylococcus aureus skin infection. Methods Mol. Biol. 1031: 109-116.

119. Todd, D. A., C. P. Parlet, H. A. Crosby, C. L. Malone, K. P. Heilmann, A. R. Horswill, and N. B. Cech (2017) Signal biosynthesis inhibition with ambuic acid as a strategy to target antibiotic-resistant infections. Antimicrob. Agents Chemother. 61: 10.1128/AAC.00263-17.

120. Quave, C. L., L. R. Plano, and B. C. Bennett (2011) Quorum sensing inhibitors of Staphylococcus aureus from Italian medicinal plants. Planta Med. 77: 188-195.

121. Quave, C. L., J. T. Lyles, J. S. Kavanaugh, K. Nelson, C. P. Parlet, H. A. Crosby, K. P. Heilmann, and A. R. Horswill (2015) Castanea sativa (European chestnut) leaf extracts rich in ursene and oleanene derivatives block Staphylococcus aureus virulence and pathogenesis without detectable resistance. PLoS One. 10: e0136486.

122. Muhs, A., J. T. Lyles, C. P. Parlet, K. Nelson, J. S. Kavanaugh, A. R. Horswill, and C. L. Quave (2017) Virulence inhibitors from Brazilian peppertree block quorum sensing and abate dermonecrosis in skin infection models. Sci. Rep. 7: 42275.

Publisher's Note Springer Nature remains neutral with regard to jurisdictional claims in published maps and institutional affiliations. 